\title{
Proteomics and functional study reveal marginal zone B and B1 cell specific protein as a candidate marker of multiple myeloma
}

\author{
VENKATESH CHANUKUPPA ${ }^{1,2}$, DEBASISH PAUL ${ }^{2,3}$, KHUSHMAN TAUNK $^{1}$, \\ TATHAGATA CHATTERJEE ${ }^{4}$, SANJEEVAN SHARMA $^{5}$, AMEY SHIROLKAR ${ }^{1}$, \\ SEHBANUL ISLAM ${ }^{2,3}$, MANAS K. SANTRA ${ }^{3}$ and SRIKANTH RAPOLE ${ }^{1}$
}

\author{
${ }^{1}$ Proteomics Laboratory, National Centre for Cell Science; ${ }^{2}$ Savitribai Phule Pune University; ${ }^{3}$ Cancer Biology and \\ Epigenetics Laboratory, National Centre for Cell Science, Pune, Maharashtra 411007; ${ }^{4}$ Army Hospital (Research and Referral), \\ Dhaula Kuan, New Delhi, Delhi 110010; ${ }^{5}$ Armed Forces Medical College, Pune, Maharashtra 411001, India
}

Received October 10, 2019; Accepted February 10, 2020

DOI: $10.3892 / \mathrm{ijo} .2020 .5056$

\begin{abstract}
Multiple myeloma (MM) is a plasma cell-associated cancer and accounts for $13 \%$ of all hematological malignancies, worldwide. MM still remains an incurable plasma cell malignancy with a poor prognosis due to a lack of suitable markers. Therefore, discovering novel markers and targets for diagnosis and therapeutics of MM is essential. The present study aims to identify markers associated with MM malignancy using patient-derived MM mononuclear cells (MNCs). Label-free quantitative proteomics analysis revealed a total of 192 differentially regulated proteins, in which 79 proteins were upregulated and 113 proteins were found to be downregulated in MM MNCs as compared to non-hematological malignant samples. The identified differentially expressed candidate proteins were analyzed using various bioinformatics tools, including Ingenuity Pathway Analysis (IPA), Protein Analysis THrough Evolutionary Relationships (PANTHER), Search Tool for the Retrieval of Interacting Genes/Proteins (STRING) and Database for Annotation, Visualization and Integrated Discovery (DAVID) to determine their biological context. Among the 192 candidate proteins, marginal zone B and B1 cell specific protein (MZB1) was investigated in detail using the RPMI-8226 cell line model of MM. The functional studies revealed that higher expression of MZB1 is associated with promoting the progression of MM pathogenesis and could be established as a potential target for MM in the future.
\end{abstract}

\section{Introduction}

Multiple myeloma (MM) is a hematological malignancy comprising of plasma cell deformation and overproduction of non-functional antibodies (1). MM is the second most

Correspondence to: Dr Srikanth Rapole, Proteomics Laboratory, National Centre for Cell Science, Pune, Maharashtra 411007, India E-mail: rsrikanth@nccs.res.in

Key words: proteomics, multiple myeloma, MZB1, LFQ, MNCs prevalent blood cancer, which accounted for $13 \%$ cases of all hematological malignancies throughout the world in 2011 (2). Infiltration of cancerous plasma cells or deposition of paraproteins in different organs, such as the kidney and in bones, is the characteristic feature of MM (3-5). Besides these features, symptoms like anemia, bone pain, kidney failure and immune deficiency are usually observed in MM (6). MM is a heterogeneous hematological malignancy and various factors are responsible for its manifestation, such as translocations $[\mathrm{t}(11 ; 14), \mathrm{t}(6 ; 14), \mathrm{t}(4 ; 14), \mathrm{t}(14 ; 16)$, and $\mathrm{t}(14 ; 20)](7)$ and hyperdiploidy of certain chromosomes i.e., 3, 5, 7, 9, 11, 15 and $19(8,9)$. However, proteins, such as CD138, HDAC-6, KSP1, AKT3, XPO1, PIM kinase, are considered to be therapeutic targets for MM that are associated with the pathogenesis of MM (10). Despite the advancement in treatment of cancer, MM still has a poor prognosis and is incurable in most cases (11).

The lack of highly-reliable markers for the early and precise diagnosis of hematological malignancies, such as MM, suggests that novel strategies are required to discover novel and reliable biomarkers for the early diagnosis and intervention to reduce the disease burden. Novel theranostic biosignatures would be one such strategy. Proteomic alterations are well-known to be associated with various diseases, including several cancers. For example, $\alpha$-fetoprotein protein expression levels were found to be altered in hepatocellular and non-seminomatous testicular cancers; CA125 protein levels were increased in ovarian, cervical, uterine and fallopian tube malignancies; prostate specific antigen levels were increased in prostate cancer and thyroglobulin protein levels were found to be upregulated in Grave's disease (12-14). Mass spectrometry based proteomics serves as a promising approach to explore and identify the alterations in expression and post-translational modifications of the proteins in the tissues, body fluids, and cells from the patient $(12,13,15-18)$. Investigating the important differentially regulated proteins and validating their functional role in the occurrence and progression of the disease could lead to the identification of novel theranostic targets.

Previously, studies have been performed in MM by investigating the serum proteomic alterations to explore the markers for this disease. Proteins, such as immunoglobulin heavy constant $\mu$, proto-oncogene diffuse B-cell lymphoma, 
$26 \mathrm{~S}$ protease regulatory subunit 4 , serum albumin and haptoglobin were found to be decreased in samples obtained from patients with MM, while actin-related protein 2/3 complex subunit 1A, immunoglobulin heavy constant $\gamma 1$, fibrinogen $\alpha$ chain fragment $\mathrm{D}$ and zinc finger protein 70 were found to be increased $(19,20)$. Similarly, MM cell lines were used to identify novel therapeutic targets for MM $(21,22)$. Recently, exportin-1 (XPO1) has been identified as a potential therapeutic target of bortezomib-mediated chemoresistance in MM using the RPMI-8226 cell line model (23). Surprisingly, the actual site of the origin of MM i.e., mononuclear cells (MNCs) has not currently been explored to identify the proteome alterations for this disease. MNCs may serve as the most appropriate cell for the identification of a dysregulated protein signature for MM that can be useful for designing novel therapeutic interventions for MM.

In the present study, the aim was to identify the proteomic alterations in MM MNCs using the label-free quantitative (LFQ) proteomic approach, which may play a crucial role in the occurrence and progression of MM.

\section{Materials and methods}

Sample collection and allocation. The present study was approved by the Ethical Committee of National Centre for Cell Science and Armed Forces Medical College (Pune, India; Institutional Review Board no. NCCS/IEC/2016-I/8). All experiments were performed according to the guidelines of ethical principles for medical research involving human subjects mentioned in the World Medical Association Declaration of Helsinki. Written informed consent was provided by all the patients recruited into the present study prior to collection of bone marrow aspirate samples. Serum protein electrophoresis (24), free light-chain diagnosis (25) and visualization of deformed plasma cells (26) are the common clinical diagnosis procedures regularly used for detection of MM. Mayo Clinic Risk Stratification for Multiple Myeloma (mSMART) and International Staging System for Myeloma are two of the guidelines/staging systems that are currently being used to diagnose multiple myeloma in clinical practise (27). All the recruited patients underwent these procedures at the hematological clinic of the Armed Forces Medical College (Pune, India). All the samples were collected between May 2014 and September 2018. A total of 32 patients with MM and 32 patients with non-hematological malignancy (anemia and idiopathic thrombocytopenic purpura; ITP), that served as controls, were recruited into the present study. Bone marrow smears of both ITP and MM samples were taken and stained with Leishman-Giemsa stain to observe the morphological changes of blood cells as described previously (28). The fresh bone marrow aspirate and serum samples from patients with MM and in the control group were collected following biopsy in BD Vacutainer ${ }^{\circledR}$ EDTA tubes and BD Vacutainer ${ }^{\mathrm{TM}} \mathrm{SST}^{\mathrm{TM}}$ II advance tubes, respectively. The samples that were collected from newly diagnosed patients with MM and non-hematological diseases was used as the inclusion criteria. Patients who suffered from comorbidities, such as hypertension, diabetes, inflammatory diseases and all other types of cancer that was not set as the inclusion criteria. The patients with MM had an mean age of $60.2 \pm 9.8$ years and patients with non-hematological malignancies had an mean age of 56.7 \pm 10.2 years. A flow chart depicting sample allocation strategy and discovery phase experimental design information is shown in Fig. 1. A total of 16 patients with MM and 16 pateints with non-hematological malignancies were randomly selected from the total number of patients from each group to be used for the discovery phase experiments. Validation experiments, such as reverse tarnscription-quantitative PCR (RT-qPCR) and western blot (WB) analysis were performed using the remaining cohort of samples that included 16 patients with $\mathrm{MM}$ and 16 patients with non-hematological malignancies. Table I provides the details of the patients recruited into the present study. For the discovery phase LFQ analysis, 16 MNCs samples were pooled (4 samples x 4 sets) to obtain $50 \mu \mathrm{g}$ protein for each set and 4 sets of experiments (biological replicates) were performed. In addition, a separate cohort of 16 samples was pooled (4 samples x 4 sets) for the validation experiments in 4 sets of biological replicates. Healthy control serum samples $(n=16)$, with a mean age of 54.6 \pm 8.2 years, serum samples from patients with MM $(n=16)$ and bone marrow interstitial fluid (BMIF; $n=16)$ from the patients with MM and control serum and control BMIF samples from patients with non-hematological malignancy were used for the WB validation of candidate proteins.

Cell culture. The human RPMI-8226 MM cell line was purchased from American Type Culture Collection. The cells were grown in RPMI-1640 medium containing $10 \%$ fetal bovine serum (FBS), $2 \mathrm{mM} \mathrm{L-glutamine} \mathrm{and} 100 \mu \mathrm{g} / \mathrm{ml}$ penicillin/streptomycin at $37^{\circ} \mathrm{C}$ in a hummidified incubator with $5 \% \mathrm{CO}_{2}$. 293T cells were kindly provided by Professor Michael R. Green (University of Massachusetts Medical School, Worcester, MA, USA). 293T cells were cultured in DMEM containing $10 \% \mathrm{FBS}$ at $37^{\circ} \mathrm{C}$ in a hummidified incubator with $5 \% \mathrm{CO}_{2}$.

Bone marrow MNCs isolation and protein extraction. Fresh bone marrow aspirate samples were collected from the patients in BD Vacutainer ${ }^{\circledR}$ EDTA tubes (Becton Dickinson and Company). Bone marrow aspirate was diluted with $1 \mathrm{X}$ PBS in a 1:5 ratio and filtered through a $100 \mu \mathrm{m}$ filter to remove bone fragments. Using the ficoll gradient centrifugation method, mononuclear cells were isolated using Histopaque ${ }^{\circledR}-1077$ according to the manufacturer's instructions (Sigma Aldrich; Merck KGaA). Briefly, the density gradient centrifugation was performed in a swing bucket centrifuge at $800 \mathrm{x}$ g for $5 \mathrm{~min}$ at room temperature. The white layer of MNCs formed in the middle of the centrifuge tube was removed and the cells washed twice with $1 \mathrm{X}$ PBS solution. Red blood cell (RBC) contamination was eliminated using RBC lysis buffer (ACK lysing buffer; cat. no. A10492-01; Thermo Fisher Scientific, Inc.). The MNCs were washed with $1 \mathrm{X}$ PBS solution and the cells were pelleted down using centrifugation at $800 \mathrm{x} g$ for $5 \mathrm{~min}$ at room temperature and final pellet was stored at $-80^{\circ} \mathrm{C}$ until required. The MNC cells from both the control and MM group were lysed using urea lysis buffer (7 M urea, $2 \mathrm{M}$ thiourea and 2\% CHAPS) as previously described by Chanukuppa et al (23). The cell lysate mixture was centrifuged at $15,000 \mathrm{x} \mathrm{g}$ for $15 \mathrm{~min}$ at $4^{\circ} \mathrm{C}$. Following centrifugation, the supernatant was collected in a fresh microcentrifuge tube and 


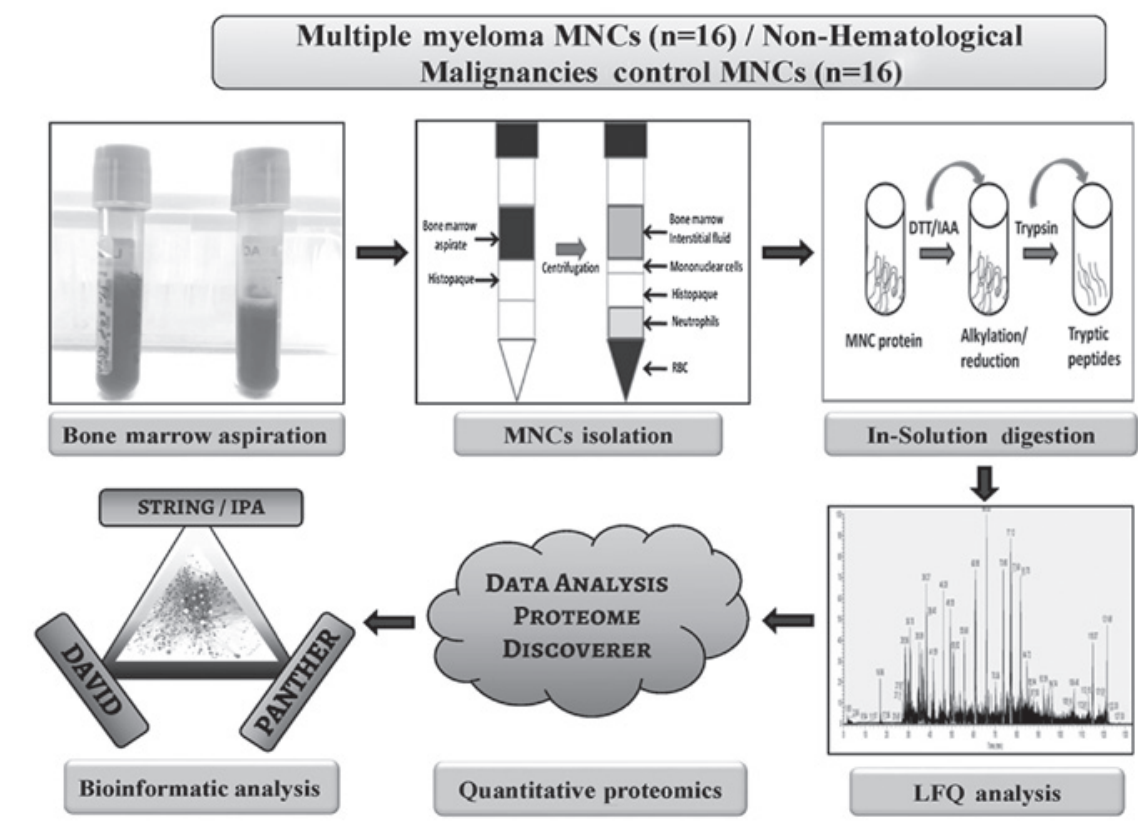

Figure 1. A flowchart depicting the sample allocation strategy and discovery phase analysis used in the multiple myeloma MNCs proteomics study. MNCs, mononuclear cells; LFQ, label-free quantitative; IPA, Ingenuity Pathway Analysis; DAVID, Database for Annotation, Visualization and Integrated Discovery; STRING, Search Tool for the Retrieval of Interacting Genes/Proteins; PANTHER, Protein Analysis THrough Evolutionary Relationships; RBC, red blood cells.

four volumes of the supernatant of pre-chilled acetone were added. The mixture was subsequently incubated overnight at $-20^{\circ} \mathrm{C}$ and the resultant precipitated protein was pelleted using centrifugation at $8,000 \mathrm{x} \mathrm{g}$ at $4^{\circ} \mathrm{C}$ for $15 \mathrm{~min}$. Furthermore, the protein pellet was resuspended in a buffer containing $7 \mathrm{M}$ urea in $50 \mathrm{mM}$ ammonium bicarbonate. A 2D Quant kit (GE Healthcare) was used to calculate the final protein concentration.

In-solution digestion and LFQ analysis. Solution based protein digestion was performed using $50 \mu \mathrm{g}$ of protein per sample as previously described (23). Briefly, each proteome sample was reduced (10 $\mathrm{mM}$ dithiothreitol), alkylated (50 $\mathrm{mM}$ iodoacetamide) and subjected to protein digestion using the proteolytic enzyme trypsin (1:50; enzyme:protein). Furthermore, the digested tryptic peptides from the MNC proteome isolated from patients with $\mathrm{MM}$ and from the control group were desalted using C18 ziptips (EMD Millipore) and reconstituted in liquid chromatography-mass spectrometry (LC-MS) grade water (J.T.Baker; Thermo Fisher Scientific, Inc.) containing $0.1 \%$ formic acid (Sigma Aldrich; Merck KGaA). A Orbitrap Fusion $^{\mathrm{TM}}$ mass spectrometer (Thermo Fisher Scientific, Inc.) coupled to an EASY-nLC ${ }^{\text {TM }} 1200$ nano-flow LC system (Thermo Fisher Scientific, Inc.) equipped with EASY-Spray column (50 cm x $75 \mu \mathrm{m}$ ID; PepMap C18 column) was used for LFQ data acquisition. For each MS data acquisition, $1 \mu \mathrm{g}$ desalted tryptic peptides from each sample were injected into the Orbitrap Fusion mass spectrometer and 4 technical replicates of each sample were used. Peptides were separated using a $5 \%$ to $95 \%$ phase B $(0.1 \%$ formic acid in $80 \%$ acetonitrile $)$ at a flow rate of $300 \mathrm{~nL} / \mathrm{min}$ for $140 \mathrm{~min}$ gradient process. The mass spectra were acquired in positive ioninzation mode with positive ionization spray voltage of $2 \mathrm{KV}$. The MS scan began with an analysis of MS1 spectrum from the mass range $375-1,500 \mathrm{~m} / \mathrm{z}$ using the Orbitrap analyzer at a resolution of 60,000; with an automatic gain control (AGC) target of $4 \times 10^{5}$ and maximum injection time of $50 \mathrm{msec}$. The precursors identified in MS1 were fragmented by high energy collision-induced dissociation and analyzed using the Orbitrap mass analyzer (NCE 35; AGC 1x10 ; maximum injection time $40 \mathrm{msec}$, resolution 15,000 at $200 \mathrm{~m} / \mathrm{z}$ ).

Data analysis for LFQ proteomics data. The identification and quantitation of proteins from the MS data was analyzed using the Proteome Discoverer software (version 2.2; Thermo Fisher Scientific, Inc.) by employing the Sequest HT database search engine with $1 \%$ false discovery rate (FDR) and the cut-off criteria of 2 missed cleavages. Database searching included all entries from the Homo sapiens (H. sapiens) UniProt reference proteome database (downloaded on 03 May 2019; https://www. uniprot.org/proteomes/UP000005640). Total protein level analysis was performed using a 10 parts per million precursor ion tolerance. The product ion tolerance used for the data analysis was $0.05 \mathrm{Da}$. Oxidation of methionine residues (+15.995 Da) was kept as a variable modification, whereas carbamidomethylation of cysteine residues (+57.021 Da) was kept as a static modification. Peptide-spectra matches (PSMs) were adjusted to a FDR of 0.01. PSMs were identified, quantified (using MS/MS fragment intensity), and narrowed down to a $1 \%$ peptide FDR and then further narrowed down to a final FDR protein level of $1 \%$ for protein-level comparisons. The sum of the area of peptide ions across all matching PSMs was used for protein quantification. Fold-change values were determined by considering the mean area values of all the triplicate samples. For further analysis, the protein abundance ratios were exported to Microsoft Excel (Microsoft Corporation). The proteomics data are available via ProteomeXchange with identifier PXD015598. 
Table I. Details of clinical subjects recruited in the study.

\begin{tabular}{|c|c|}
\hline Criteria & No. of subjects \\
\hline Patients with MM & 32 \\
\hline \multicolumn{2}{|l|}{ Sex } \\
\hline Male & 18 \\
\hline Female & 14 \\
\hline Discovery phase & 16 \\
\hline Validation phase & 16 \\
\hline Mean age at surgery, years (range) & $60.2 \pm 9.8(46-78)$ \\
\hline $\begin{array}{l}\text { Preoperative Radiotherapy or } \\
\text { chemotherapy }\end{array}$ & No \\
\hline MM clonal plasma cells, $\% \pm \mathrm{SD}$ & $65 \pm 20$ \\
\hline $\begin{array}{l}\text { Patients with non-hematology } \\
\text { malignancy }\end{array}$ & 32 \\
\hline \multicolumn{2}{|l|}{ Sex } \\
\hline Male & 18 \\
\hline Female & 14 \\
\hline Discovery phase & 16 \\
\hline Validation phase & 16 \\
\hline $\begin{array}{l}\text { Mean age at blood collection, } \\
\text { years (range) }\end{array}$ & $57.3 \pm 10.2(43-65)$ \\
\hline $\begin{array}{l}\text { Preoperative Radiotherapy or } \\
\text { chemotherapy }\end{array}$ & No \\
\hline MM clonal plasma cells, $\% \pm \mathrm{SD}$ & NA \\
\hline Healthy Controls & 16 \\
\hline \multicolumn{2}{|l|}{ Sex } \\
\hline Male & 9 \\
\hline Female & 7 \\
\hline Validation phase & 16 \\
\hline $\begin{array}{l}\text { Mean age at blood collection, } \\
\text { years (range) }\end{array}$ & $54.6 \pm 8.2(41-60)$ \\
\hline $\begin{array}{l}\text { Preoperative Radiotherapy or } \\
\text { chemotherapy }\end{array}$ & No \\
\hline MM clonal plasma cells, $\% \pm \mathrm{SD}$ & NA \\
\hline
\end{tabular}

MM, multiple myeloma.

Functional and interaction analysis using bioinformatics tools. The statistically significant differentially expressed (DE) proteins identified from the MS data analysis were subjected to different bioinformatics analyses to understand their biological context and their involvement in the pathophysiology of MM. Proteins that were significantly DE $\left(\mathrm{P}<0.05\right.$ and $\log _{2}$ fold-change $\left(\log _{2} \mathrm{FC}\right)$ value of $\left.\geq 1.0 / \leq-1.0\right)$ in samples from patients were analyzed using Ingenuity Pathway Analysis (IPA), Protein Analysis THrough Evolutionary Relationships (PANTHER; version 14.1; http://www.pantherdb.org/), Search Tool for the Retrieval of Interacting Genes/Proteins (STRING; https://string-db. org; version 11.0) with parameters like multiple proteins, homo sapiens as the organism and Database for Annotation,
Visualization and Integrated Discovery (DAVID; version 6.8; http://david.abcc.ncifcrf.gov/home.jsp). Parameters, such as functional annotation, UniProt accession as identifier ID as well as extracted biological functions and pathways were selected for DAVID based bioinformatic analysis. Similarly, for PANTHER analysis, parameters, including $H$. sapiens as an organism, and the functional classifications viewed graphically for selected analysis, and the export of the molecular functions, biological processes, protein classes and pathways were used.

BMIF and serum protein extraction. The bone marrow aspirate and peripheral blood samples were collected from patients with MM and patients with non-hematological malignancies, and incubated at room temperature for $30 \mathrm{~min}$, and subsequently centrifuged at $3,000 \mathrm{xg}$ for $10 \mathrm{~min}$ at $10^{\circ} \mathrm{C}$ to separate the BMIF and the serum. The BMIF and the serum were thawed, and an albumin and immunoglobulin $(\mathrm{Ig}) \mathrm{G}$ depletion kit (GE Healthcare) was used to remove the most abundant proteins, such as albumin and $\operatorname{IgG}$ from these biological fluids. Subsequently, the depleted samples were desalted using a 2D clean-up kit (GE Healthcare). The obtained protein pellet was dissolved in urea lysis buffer (7 M urea, $2 \mathrm{M}$ thiourea and $2 \%$ CHAPS) and the protein content was quantified using $2 \mathrm{D}$ Quant kit (GE Healthcare).

RNA extraction and RT- $q P C R$ analysis. Total RNA was extracted from MNCs in patients with MM and from the control group using TRIzol ${ }^{\circledR}$ reagent (Invitrogen; Thermo Fisher Scientific, Inc.). The total RNA was quantified using a Nanodrop 2000C (Thermo Fisher Scientific, Inc.) and a denaturing agarose gel was used for quality control. The PrimeScript cDNA synthesis kit (Takara Biotechnology Co., Ltd.), was used to synthesize the first-strand cDNA according to the manufacturer's protocol, with $1 \mu \mathrm{g}$ of total RNA. The qPCR was performed to measure the mRNA level of MZB1 (forward primer, 5'-ACAACTGGATGATGAGGAG-3' and reverse 5'-ACATCTGGTAAGCCACAG-3') using SYBR-Green as part of a kit (cat. no. RR82WR; Takara Biotechnology Co., Ltd.). The thermocyclying conditions used were as follows: Initial denaturation for $2 \mathrm{~min} 95^{\circ} \mathrm{C}$, and $95^{\circ} \mathrm{C}$ for $15 \mathrm{sec}, 57.2^{\circ} \mathrm{C}$ for $30 \mathrm{sec}$, and $72^{\circ} \mathrm{C}$ for $30 \mathrm{sec}$ for 39 cycles. The experiments were performed in four biological replicates and each replicate consisted of pooling MNCs from four patients. The analysis of relative expression for MZB1 was calculated by normalizing the data with GAPDH (forward primer: 5'-CAATGACCCCTT CATTGACC-3' and reverse, 5'-GACAAGCTTCCCGTTCTC AG-3') as an internal control, using the $2^{-\Delta \Delta C q}$ method (29).

Generation of stable knockdown of RPMI-8226 cells. Stable knockdown in RPMI-8226 cells of the identified target protein (MZB1) were constructed using the short hairpin (sh)RNA mediated knockdown approach as previously described (23). In brief, the shRNA-MZB1 vector, with a concentration of $1 \mu \mathrm{g}$, was transfected into 293T cells using polyethylene amine (Sigma Aldrich; Merck KGaA). A total of 3 shRNAs were used, including shMZB1_1 (cat. no. TRCN0000372920), shMZB1_2 (cat. no. TRCN0000165757), shMZB1_3 (cat. no. TRCN0000165010) (all Sigma Aldrich; Merck KGaA). A scramble shRNA was used as the control (5'-TCTCGCTTG 
GGCGAGAGTAAG-3'; Thermo Fisher Scientific, Inc.). The culture transfected $293 \mathrm{~T}$ cells with infectious culture media were harvested and the viruses were collected after 72 h. For the next 3 days, RPMI-8226 cells were incubated with the virus solution in the presence of polybrene $(10 \mu \mathrm{g} / \mathrm{ml}$; cat. no. TR-1003; Sigma Aldrich; Merck KGaA). Subsequently, the infected cells were cultured in the presence of puromycin $(1.0 \mu \mathrm{g} / \mathrm{ml})$ for 10 days.

WB analysis. The protein concentration in each of the MNCs, serum and BMIF samples from patients with MM $(n=16)$ and in the control group $(n=16)$ was calculated using the 2D-Quant kit (GE Healthcare) prior to WB analysis. WB analysis was performed as previously described (30). In brief, MNCs, serum and BMIF proteins were electrophoretically resolved on a $12 \%$ SDS-PAGE gel ( $40 \mu \mathrm{g}$ per well) and transferred onto the PVDF membranes, under wet conditions using Mini Trans-Blot ${ }^{\circledR}$ Cell transfer unit (Bio-Rad Laboratories, Inc.). Blocking was performed using 5\% skimmed milk at room temperature for $1 \mathrm{~h}$. WB analysis was performed using a monoclonal/polyclonal primary antibody against human MZB1 (1:250 dilution; cat. no. HPA043745; Sigma Aldrich; Merck KGaA), $\beta$-actin (1:2,500 dilution; cat. no. A2228; Sigma Aldrich; Merck KGaA), $\beta$-tubulin (1:2,500 dilution; cat. no. T0198; Sigma Aldrich; Merck KGaA). Incubation with the primary antibody was performed overnight at $4^{\circ} \mathrm{C}$. The anti-mouse cat. no. NXA931-1ML) and anti-rabbit (NA934-1ML; both GE Healthcare) secondary antibodies conjugated with horseradish peroxidase were subsequently used at room temperature for $1 \mathrm{~h}$. Following which, the blots were treated with a chemiluminescent substrate (cat. no. 170-5067; Bio-Rad Laboratories, Inc.) and the bands were visualized using Image Quant LAS 4000 imaging system (GE Healthcare) and ImageJ version 2 software (National Institutes of Health) was used for the densitometry analysis.

For the knockdown experiments, the proteins from RPMI-8226 control cells and RPMI-8226-MZB1 knockdown cells, using shMZB1_3, were extracted as previously described (23). Antibodies against cyclin A, cyclin B, cyclin D, AKT, pAKT (Ser473), ERK, pERK were obtained from Santa Cruz Biotechnology, Inc. The quantification of the proteins was performed and the samples were subjected to WB analysis as aforementioned. In additon, WB analysis was also performed to examine the protein levels of MZB1 in culture media of RPMI-8226 control cells and RPMI-8226-MZB1 knockdown cells as previously described (31). We normalized the amount of media supernatant to be loaded on SDS-PAGE based on equal cell number $\left(3 \times 10^{5}\right)$

Cell proliferation assay. The cell proliferation of RPMI-8226 and RPMI-8226-sh-MZB1 cells was measured using the Trypan blue dye as previously described (32). In brief, an equal number of RPMI-8226 and RPMI-8226-sh-MZB1 cells were seeded. The cell number of the first-day was considered as the zero time point. After every 24-h interval, the cells were counted using the Trypan blue dye and a hemocytometer using an Olympus light microscope (cat. no. 1X2-SP; Olympus Corporation) using x10 objective. The zero time point was taken as $100 \%$ cells. The experiment was repeated three times.
Fluorescence-activated cell sorting (FACS) based cell cycle analysis. RPMI-8226 cells with/without knockdown of MZB1, in exponential growth phase, were collected and washed three times with ice cold $1 \mathrm{X}$ PBS. The cells were washed with $95 \%$ chilled ethanol and incubated at $4^{\circ} \mathrm{C}$ for $24 \mathrm{~h}$ for cell fixation. Prior to FACS acquisition, the ethanol fixed cells were rinsed with ice cold $1 \mathrm{X}$ PBS and stained with propidium iodide $(50 \mu \mathrm{g} / \mathrm{ml})$ and RNAse $(50 \mu \mathrm{g} / \mathrm{ml})$ in $1 \mathrm{X}$ PBS at $37^{\circ} \mathrm{C}$ in the dark for $30 \mathrm{~min}$. A BD FACS Calibur cell analyzer (BD Biosciences) was used to perform cell cycle analysis. The cell cycle data analysis was performed using Cell Quest Pro software (BD Biosciences).

Softagar colonyformation assay. Toevaluate the effect of MZB1 knockdown on the RPMI-8226 MM cell line soft agar colony formation assay was performed as previously described (33). Briefly, the cells (RPMI-8226 and RPMI-8226-sh-MZB1) were collected after $48 \mathrm{~h}$ of culture at $37^{\circ} \mathrm{C}$ with $5 \% \mathrm{CO}_{2}$. Cell culture dishes were filled with $0.6 \%$ base agar (Invitrogen; Thermo Fisher Scientific, Inc.) and 2X RPMI-1640 with 20\% FBS and allowed to solidify. Following which, 5,000 RPMI-8226 and RPMI-8226-sh-MZB1 cells were suspended in $0.3 \%$ of agar containing $20 \%$ FBS and were placed on the top of the base agar. Cells were observed using an Olympus light microscope (cat. no. 1X2-SP; Olympus Corporation) using x20 objective and images were obtained after 20 days.

Statistical analysis. To determine the significant differences of all the data sets, statistical analysis was performed using GraphPad Prism software (version 7.0; GraphPad Software, Inc.). Comparisons between two groups (control vs. MM) was performed using Student's t-test, while datasets containing 3 groups (RPMI-8226, RPMI-8226-sh-MZB1_2 and RPMI-8226-sh-MZB1_3) were analyzed using one-way ANOVA followed by Tukey's post hoc multiple comparisons test. The experiments were repeated independently 3 times. The mean \pm SD of each biological triplicate samples were used for data representation.

\section{Results}

Comparative proteomic analysis of bone marrow MNCs in $M M$. To identify the DE proteins in MNCs from patients with MM compared to the MNCs from patients with non-hematological malignancies, LFQ-based quantitative proteomic analysis was performed. Representative microscopic images for the ITP and MM are shown in Fig. S1A and S1B. A total of 4 biological triplicate experiments from MNCs from patients with MM and patients with non-hematological malignant MNCs, as controls, were analysed using a Orbitrap Fusion mass spectrometer. Proteomic analysis identified 715 common proteins from the total dataset, out of which 192 proteins were DE. Among these DE proteins, the expression of 79 proteins was upregulated and 113 proteins showed a downregulated pattern (Fig. 2A). The proteins with $\log _{2} \mathrm{FC}$ values $\geq 1.0$ were considered as upregulated proteins and those with $\log _{2} \mathrm{FC}$ values of $\leq-1.0$ were considered as downregulated proteins. All the DE proteins included in the present study were highly significant with an FDR value $\leq 0.01$ and $\mathrm{P} \leq 0.05$. The list of all the DE proteins along with FCs are shown in Table SI. 
A

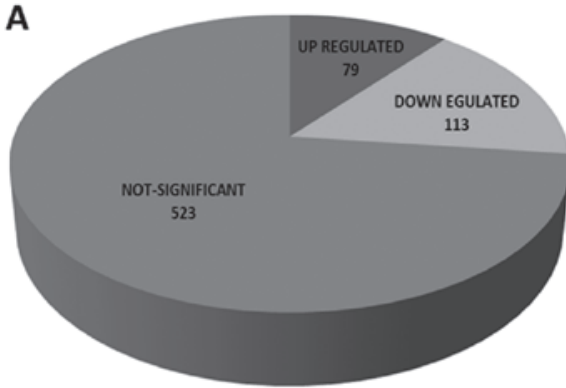

C

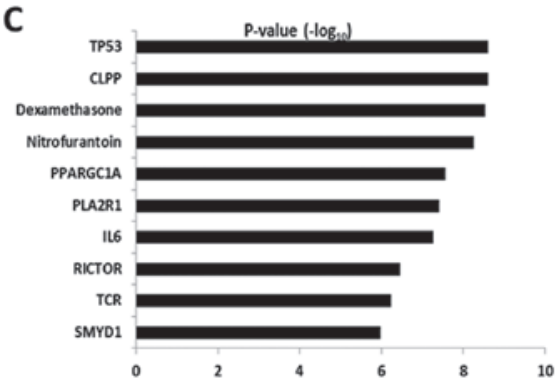

B

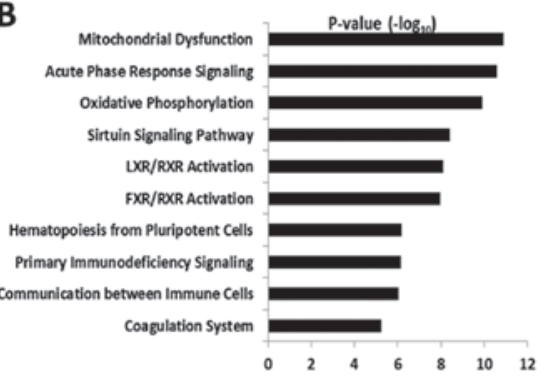

D

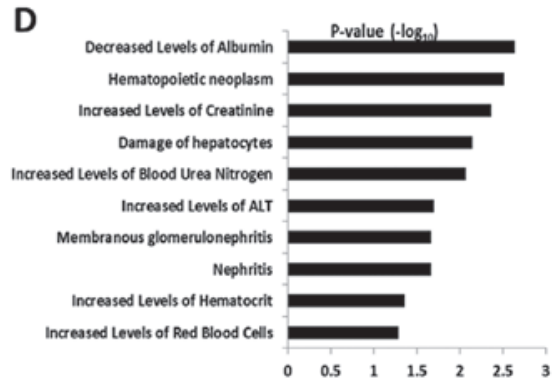

Figure 2. Bioinformatic analysis of the DE protein dataset. (A) Venn diagram analysis for the DE proteins. IPA-based (B) canonical pathways, (C) upstream regulators and (D) toxicology functions of the upregulated proteins. DE, differentially expressed; IPA, Ingenuity Pathway Analysis.

Bioinformatics based functional and interaction analysis. The 192 statistically significant DE proteins, identified from the LFQ-based quantitative proteomic analysis, were selected for bioinformatic analysis to understand and elucidate the biological role of these proteins in MM. The bioinformatic tools, IPA, DAVID and PANTHER, were used to identify the molecular functions, biological processes, protein classes and pathways that were altered in MNCs from patients with MM. The analysis using DAVID revealed that the upregulated proteins were involved in biological processes, such as 'platelet degranulation', 'regulation of complement activation', 'complement activation classical pathway', 'receptor-mediated endocytosis' and 'complement activation' (the top 10 are shown in Fig. S2A). The key molecular functions identified to be altered in the upregulated proteins were 'immunoglobulin receptor binding', 'antigen binding', 'structural constituent of the cytoskeleton', 'serine-type endopeptidase activity' and 'chaperone binding' (the top 10 are shown in Fig. S2B). In addition, various cancer-associated pathways were also found to be altered in the upregulated proteins, including 'platelet degranulation', 'respiratory electron transport', 'regulation of complement cascade', 'scavenging of heme from plasma' and 'the formation of tubulin folding intermediates' (the top 10 are shown in Fig. S2C). Similarly, the downregulated proteins identified from MNCs in patients with MM were found to be involved in biological processes, such as 'cell-cell adhesion', 'movement of a cell or subcellular component', 'small GTPase mediated signal transduction', 'inflammatory response' and 'glycolytic process' (the top 10 are shown in Fig. S3A). The key molecular functions found to be altered in the downregulated proteins include 'cadherin binding', 'RAGE receptor binding', 'GTPase activity', 'GDP binding', 'GTP binding' and 'calcium-dependent protein binding' (the top 10 are shown in Fig. S3B). In additon, the downregulated proteins were found to be involved in pathways, such as 'advanced glycosylation endproduct', 'platelet degranulation', 'glycolysis', 'gluconeogenesis' and 'EPHB-mediated forward signaling' (the top 10 are shown in Fig. S3C). Furthermore, bioinformatics analysis using PANTHER, to provide further insights, was also performed to obtain molecular functions, biological processes, protein classes and pathways involved in the DE proteins, which revealed different result (Figs. S4 and S5). PANTHER analysis of the upregulated proteins showed alterations in molecular functions, such as 'transporter activity', 'catalytic activity', 'molecular function regulator' and 'structural molecule activity'. In addition, biological processes such as 'immune system process', 'metabolic process,' and biological regulation and adhesion were also found to be altered. Furthermore, the upregulated proteins belonged to protein classes, such as chaperone, transporter, oxidoreductase and enzyme modulator, while the key pathways that were identified included 'blood coagulation', 'FAS signaling pathway', 'cytoskeletal regulation by @ GTPase' and 'CCKR signalling map'. Similarly, PANTHER analysis of the downregulated proteins showed alterations in molecular functions such as transporter activity, 'catalytic activity', 'binding activity' and 'structural molecule activity'. In addition, biological processes, such as 'cellular process', 'localization', 'immune system process' and 'metabolic process' were also found to be altered. Furthermore, downregulated proteins were associated with protein classes, such as 'enzyme modulator' 'chaperone', 'transferase' and 'oxidoreductase', while the key pathways identified included 'p53 pathway', 'ubiquitin proteasome pathway', 'interferon $\gamma$ signalling pathway', and 'integrin signaling pathway'. The protein-protein interactions (PPI) between the upregulated proteins were determined using the online software STRING. From the 79 upregulated proteins, 67 nodes were found to be interacting with each other and these PPIs are shown in Fig. S6. The MZB1 protein showed direct interaction with immunoglobulin J chain (IGJ) protein, 
Table II. A partial list of significantly differentially expressed proteins identified using label-free quantitative analysis in mononuclear cells from patients with multiple myeloma as compared with patients with non-hematology malignancies.

A, Upregulated proteins

\begin{tabular}{|c|c|c|c|c|}
\hline Accession ID & Description & Fold-change & P-value & FDR adjusted P-value \\
\hline P30043 & Flavin reductase NADPH & 22.801 & $2.46 \times 10^{-7}$ & $2.4 \times 10^{-6}$ \\
\hline A0A0J9YXX1 & Immunoglobulin heavy variable 5-10-1 & 19.497 & $4.62 \times 10^{-5}$ & $9.59 \times 10^{-5}$ \\
\hline P01023 & $\alpha$-2-macroglobulin & 17.171 & $4.32 \times 10^{-5}$ & $9.03 \times 10^{-5}$ \\
\hline P08603 & Complement factor $\mathrm{H}$ & 15.636 & $2.93 \times 10^{-6}$ & $1.20 \times 10^{-5}$ \\
\hline P04003 & C4b-binding protein $\alpha$ chain & 14.925 & $1.28 \times 10^{-4}$ & $2.41 \times 10^{-4}$ \\
\hline P04004 & Vitronectin & 14.556 & $1.47 \times 10^{-5}$ & $3.95 \times 10^{-5}$ \\
\hline P01011 & $\alpha$-1-antichymotrypsin & 12.607 & $8.41 \times 10^{-5}$ & $1.64 \times 10^{-4}$ \\
\hline P80748 & Immunoglobulin $\lambda$ variable $3-21$ & 12.425 & $2.95 \times 10^{-5}$ & $6.64 \times 10^{-5}$ \\
\hline $\mathrm{A} 0 \mathrm{~A} 0 \mathrm{~B} 4 \mathrm{~J} 2 \mathrm{~B} 5$ & $\begin{array}{l}\text { Immunoglobulin heavy variable 3/OR } 16-9 \\
\text { non-functional fragment }\end{array}$ & 11.104 & $4.51 \times 10^{-5}$ & $9.39 \times 10^{-5}$ \\
\hline P0DOY3 & Immunoglobulin $\lambda$ constant 3 & 11.092 & $2.43 \times 10^{-5}$ & $5.67 \times 10^{-5}$ \\
\hline P01859 & Immunoglobulin heavy constant $\gamma 2$ & 10.814 & $1.12 \times 10^{-4}$ & $2.14 \times 10^{-4}$ \\
\hline Q8WU39a & marginal zone B and B1 cell specific protein & 10.579 & $5.47 \times 10^{-4}$ & $8.74 \times 10^{-4}$ \\
\hline P02647 & Apolipoprotein A-I & 9.982 & $3.93 \times 10^{-5}$ & $8.42 \times 10^{-5}$ \\
\hline P01591 & Immunoglobulin $\mathrm{J}$ chain & 9.808 & $1.60 \times 10^{-5}$ & $4.22 \times 10^{-5}$ \\
\hline
\end{tabular}

B. Downregulated proteins

\begin{tabular}{|c|c|c|c|c|}
\hline Accession ID & Description & Fold-change & P-value & FDR adjusted P-value \\
\hline P02775 & Platelet basic protein & 0.124 & $1.13 \times 10^{-9}$ & $2.12 \times 10^{-7}$ \\
\hline Q05315 & Galectin-10 & 0.130 & $4.61 \times 10^{-9}$ & $3.02 \times 10^{-7}$ \\
\hline P35754 & Glutaredoxin-1 & 0.150 & $1.47 \times 10^{-8}$ & $6.32 \times 10^{-7}$ \\
\hline P07384 & Calpain-1 catalytic subunit & 0.217 & $4.69 \times 10^{-6}$ & $1.69 \times 10^{-5}$ \\
\hline P04908 & Histone $\mathrm{H} 2 \mathrm{~A}$ type $1-\mathrm{B} / \mathrm{E}$ & 0.245 & $9.02 \times 10^{-7}$ & $5.61 \times 10^{-6}$ \\
\hline P32320 & Cytidine deaminase & 0.249 & $1.62 \times 10^{-9}$ & $2.12 \times 10^{-7}$ \\
\hline P52566 & Q-GDP-dissociation inhibitor 2 & 0.250 & $1.25 \times 10^{-6}$ & $6.73 \times 10^{-6}$ \\
\hline P84095 & Q-related GTP-binding protein $\varrho G$ & 0.253 & $2.62 \times 10^{-7}$ & $2.40 \times 10^{-6}$ \\
\hline P09960 & Leukotriene A-4 hydrolase & 0.255 & $4.44 \times 10^{-8}$ & $1.05 \times 10^{-6}$ \\
\hline O75131 & Copine-3 & 0.261 & $7.72 \times 10^{-9}$ & $4.06 \times 10^{-7}$ \\
\hline P48595 & Serpin B10 & 0.262 & $4.77 \times 10^{-8}$ & $1.07 \times 10^{-6}$ \\
\hline P61978-3 & $\begin{array}{l}\text { Isoform } 3 \text { of Heterogeneous nuclear } \\
\text { ribonucleoprotein } \mathrm{K}\end{array}$ & 0.264 & $1.04 \times 10^{-6}$ & $5.98 \times 10^{-6}$ \\
\hline E7EUC7 & UTP - glucose-1-phosphate uridylyltransferase & 0.265 & $7.65 \times 10^{-8}$ & $1.29 \times 10^{-6}$ \\
\hline P05109 & Protein S100-A8 & 0.269 & $1.02 \times 10^{-7}$ & $1.38 \times 10^{-6}$ \\
\hline P05089 & Arginase-1 & 0.270 & $2.54 \times 10^{-8}$ & $7.83 \times 10^{-7}$ \\
\hline
\end{tabular}

FDR, false discover rate.

indicated with a red circle and a high confidence level of interaction, which suggests it has a significant role in the assembly and secretion of antibodies from the plasma cells (Fig. S6). In addition, other proteins, such as ECH, NDUFS3, UQCRC1, COXS8, ATP1A1, SLC4A1 and SPTA1 were found to interact strongly with the identified upregulated proteins. Furthermore, proteins, including APOA1, CP, HPX, APOH, VTN, C4BPA and $\mathrm{C} 3$ also showed strong interactions with the upregulated proteins from STRING analysis.
IPA analysis was subsequently performed by analyzing the MS data from the 79 upregulated proteins, including their P-values and FCs. Pathways, such as 'mitochondrial dysfunction', 'acute phase response signaling', 'oxidative phosphorylation', 'sirtuin signaling pathway' and 'LXR/RXR activation' were activated in MNCs from patients with MM (Fig. 2B). Upstream regulators like TP53, CLPP, dexamethasone, nitrofurantoin, PPARGC1A and IL6 were found to be amongst the top $10 \mathrm{DE}$ proteins (Fig. 2C). By analyzing the 

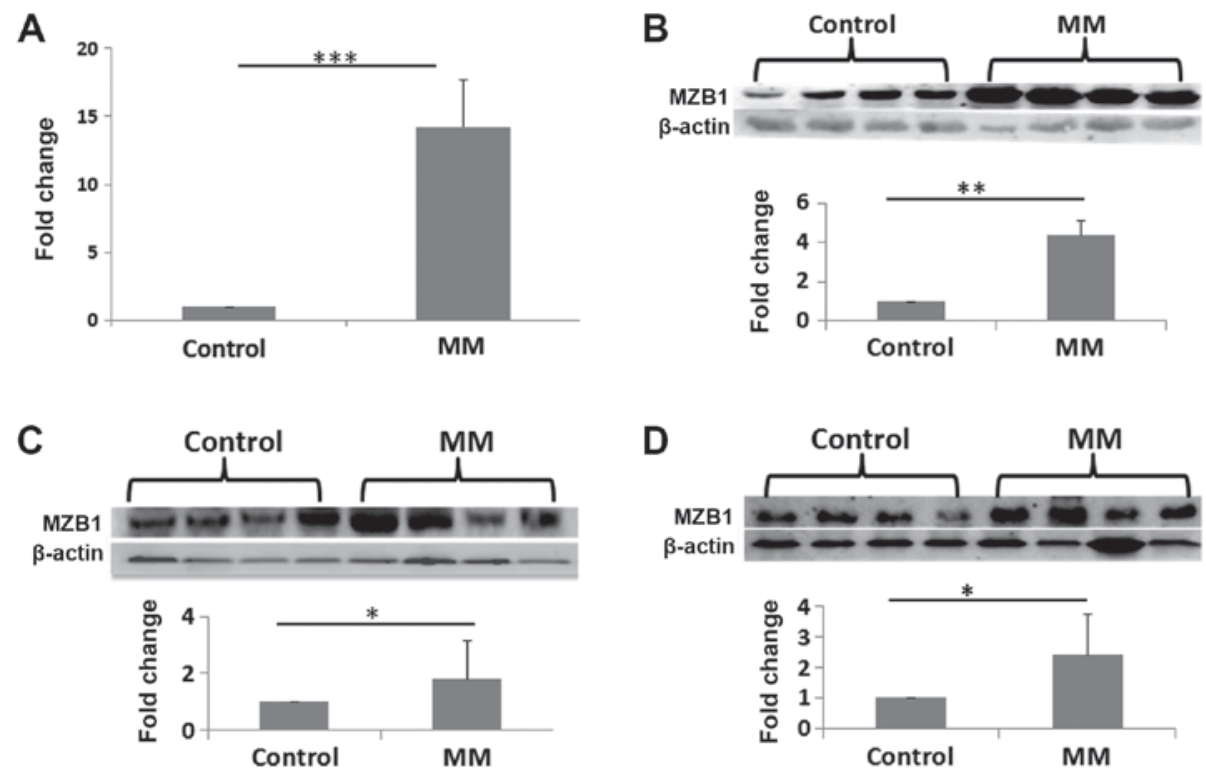

Figure 3. Validation experiments for the analysis of the MZB1 protein in MNCs from patients with MM and with non-hematological malignancies. (A) mRNA and (B) protein expression level of MZB1 using reverse transcription-quantitative PCR and western blot analysis, respectively. mRNA fold-change, 14.25. Protein fold-change, 4.62 (C) Protein expression levels of MZB1 from serum samples. The first four lanes are from healthy controls and last four lanes are from patients with MM. Fold-change, 1.78 (D) Protein expression levels of MZB1 in BMIF. The first four lanes are from patients with non-hematological malignancies and the last four lanes are from patients with MM. Fold-change, 2.36 . ${ }^{*} \mathrm{P} \leq 0.05,{ }^{* * *} \mathrm{P} \leq 0.01,{ }^{* * *} \mathrm{P} \leq 0.001$. BMIF, bone marrow intersitital fluid; MM, multiple myeloma; MZB1, marginal zone B and B1 cell specific protein.

toxicology functions, the upregulated proteins were found to be involved in the decreased levels of albumin, hematopoietic neoplasm, increased levels of creatinine, damaged hepatocytes and increased levels of blood urea nitrogen (Fig. 2D). IPA based interactions for the MZB1 protein are shown in Fig. S7. The red color indicates proteins that were identified in the present study and the proteins without colour were not identified. IPA based interactions revealed that MZB1 interacts with Ig, such as Ig heavy constant mu (IGHM), IgA, IgG, IgM, IGH $\gamma 3$, Ig Jchain, IgG1, IgG3 and IGHG2. These results are a characteristic feature of MM in which antibodies are overproduced. MZB1 also showed strong interactions with CLU, as shown in Fig. S7.

Selection of candidate proteins. Among the statistically significant proteins, MZB1 $\left(\log _{2}\right.$ FC, 3.4) was selected for further functional studies using the MM cell line model, as this protein was one of the significantly DE proteins (Table II) and it also has significant roles in cell proliferation as well as immunoglobulin synthesis (34). Furthermore, functions of MZB1 are associated with characteristic features of MM, such as calcium homeostasis, immunoglobulin production and cell replication (35). The majority of the significantly DE proteins were also found to be immunoglobulins, which are known to be dysregulated in MM. MZB1 was found to be upregulated in the present study and notably, this protein is least explored in the context of hematological malignancies.

Validation of MZB1 using RT-qPCR and WB analysis. Quantitative gene expression analysis of MZB1 was performed using RT-qPCR. The qPCR data revealed that mRNA levels of MZB1 were significantly increased at the transcriptional level (Fig. 3A). Similarly, WB analysis also revealed that expression levels of MZB1 were significantly increased in MNCs from patients with MM compared with that in the control samples (Fig. 3B). To further confirm this result, the expression level of MZB1 in the serum and in BMIF from patients with MM, and in patients with non-hematological malignancies were analyzed. There was upregulation of MZB1 in the patients with MM compared with that in the control group. Representative WB images are shown in Fig. $3 \mathrm{C}$ and D. In addition, the expression level of MZB1 in the culture media of RPMI-8226 and knockdown of MZB1 in RPMI-8226 was investigated and the protein expression levels of MZB1 in RPMI-8226 cells with knockdown of MZB1 secretome was lower (Fig. S8).

MZB1 promotes the proliferation of RPMI-8226 cells. To investigate the role of MZB1 in MM progression, MZB1 stably knocked down in RPMI-8226 cells using lentivirus shRNA interference in RPMI-8226 cells (Fig. 4A). There was marked attenuation of the MZB1 protein expression level in RPMI-8226 cells using multiple shRNA, validating the target effect of RNA interference. Subsequently the proliferation of RPMI-8226 cells with stable knockdown of MZB1 was investigated, using shMZB1_2 and shMZB1_3, as they knocked down MZB1 expression more effectively. The results revealed that the depletion of MZB1 results in a slower proliferation of RPMI-8226 cells (Fig. 4B). To further examine how knockdown of MZB1 led to the reduction in cell proliferation, flow cytometry was performed to examine the number of apoptotic cells. The results revealed that the knockdown of MZB1 (in RPMI-8226-shMZB1_2 and RPMI-8226-shMZB1_3 expressing cells) significantly increased the sub-G1 cell population i.e., apoptotic cells (Fig. 4C). Representative flow cytometry analysis plots were shown in Fig. S9.

Cancer cells grow in an anchorage-independent manner (36). As RPMI8226 grow in suspension, it was investigated whether MZB1 has any role in anchorage-independent 
A

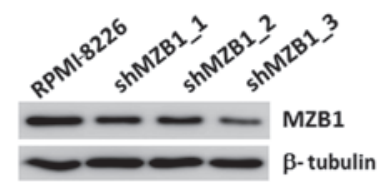

B

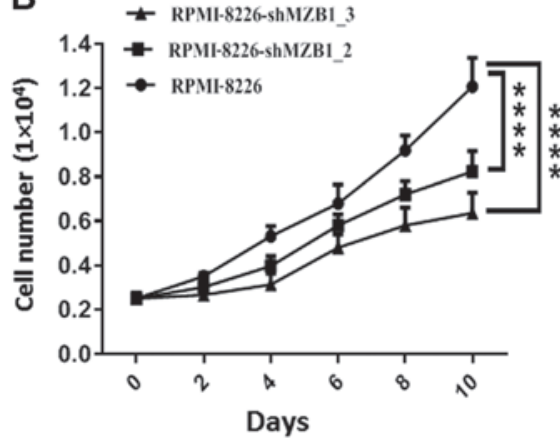

C

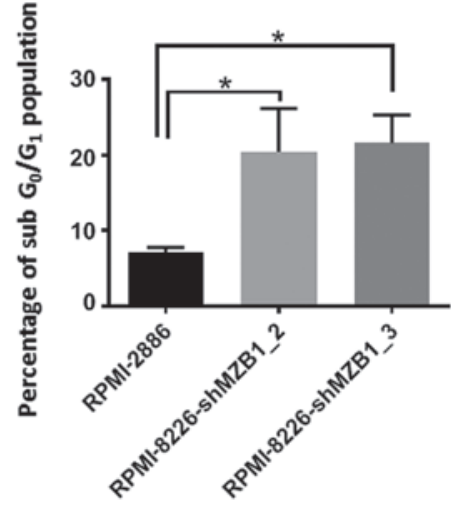

Figure 4. MZB1 plays a critical role in the proliferation of RPMI-8226 cells. (A) Whole cell protein extracts from RPMI-8226 cells expressing either scramble shRNA or targeted shRNA for knockdown of MZB1 were detected for the MZB1 and $\beta$-tubulin proteins using western blot analsysis. (B) Cell proliferation assay revealed that MZB1 promotes proliferation of RPMI-8226 cells. RPMI-8226 cells expressing either scramble shRNA (NS) or targeted shRNA against MZB1 were counted using trypan blue dye at the indicated time times. (C) Flow cytometry analysis revealed an increase in the sub- $\mathrm{G}_{1}$ population following knockdown of MZB1. The experiment was repeated three times and the data is presented as mean $\pm \mathrm{SD}$. ${ }^{*} \mathrm{P} \leq 0.05$, ${ }^{* * * *} \mathrm{P} \leq 0.0001$. sh, short hairpin; MZB1, marginal zone B and B1 cell specific protein.
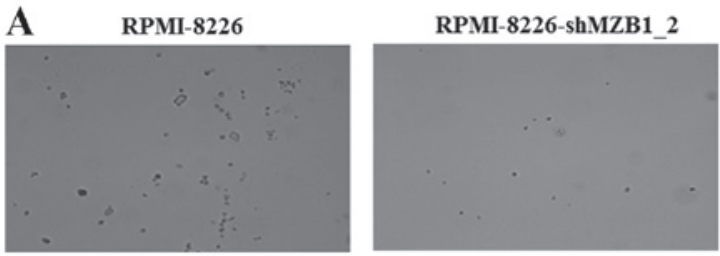

RPMI-8226-shMZB1 3

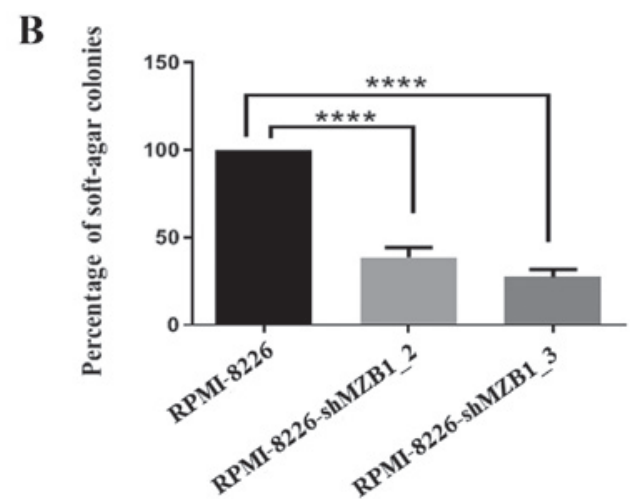

Figure 5. MZB1 is involved in the proliferation of RPMI-8226 MM cell line. (A) Representative images of the soft agar colonies for RPMI-8226 cells expressing scramble shRNA, RPMI-8226-shMZB1_2 and RPMI-8226-shMZB1_3 cells. (B) Quantification of colony formation assay of RMI 8226 cells expressing either scramble shRNA or targeted shRNA against MZB1. The experiment was repeated three times and the data is presented as mean $\pm \mathrm{SD}$. ${ }^{* * * *} \mathrm{P} \leq 0.0001$. sh, short hairpin; MZB1, marginal zone B and B1 cell specific protein.

growth of RPMI-8226 cells using soft agar colony formation assays. It was found that knockdown of MZB1 resulted in inhibition of anchorage-independent growth of the RPMI-8226 cells, indicating that MZB1 might regulate growth proliferation-associated proteins (Fig. 5). Therefore, the proteins associated with the cell cycle progression in the control and MZB1 knockdown cells were investigated. WB results revealed that the expression of numerous proteins that are associated with promoting cell cycle progression (37-41) were reduced in MZB1 knockdown RPMI-8226 cells (Fig. 6). For example, the phosphorylated forms of AKT and MAPK proteins were markedly inhibited in MZB1 knockdown RPMI-8226 cells. Similarly, cyclins involved in $\mathrm{G}_{1}$ phase (cyclin D1), S phase (cyclin $A$ ) and $G_{2} / M$ phase (cyclin $A$ and cyclin $B$ ) were 


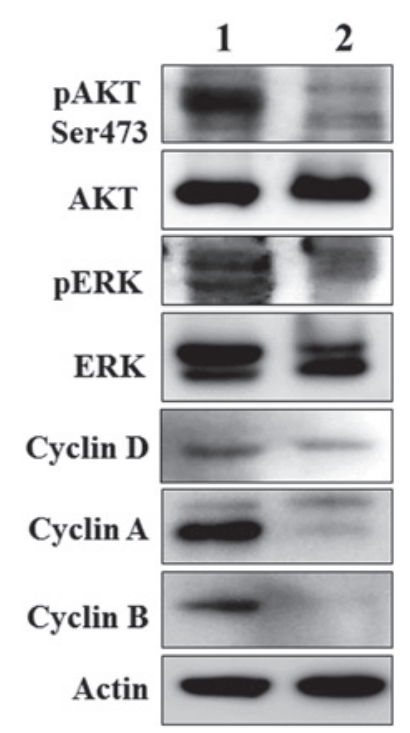

Figure 6. MZB1 regulates the proliferation markers in multiple myeloma RPMI-8226 cell line. Whole-cell lysates of RPMI-8226 cells expressing either scramble shRNA (lane 1) or targeted shRNA against MZB1 (lane 2) were analyzed for the indicated proteins using western blot analysis. MZB1, marginal zone B and B1 cell specific protein; sh, short hairpin.

markedly reduced in MZB1 knockdown RPMI-8226 cells, suggesting that MZB1 is important for proliferation of MM. Taken together, the results of the present study suggest that the elevated level of the MZB1 plays a crucial role in MM.

\section{Discussion}

Worldwide, MM, the second most prevalent hematological malignancy, is comprised of deformed plasma cells, which leads to overproduction of antibodies (1). MM accounts for nearly $13 \%$ of all known hematologic malignancies (42). In developing countries, such as India, 4/100,000 individuals are diagnosed with MM (43). Approximately 24,280 to 30,330 new MM cases were detected and 12,650 deaths occured in 2016 in the United States (44). Although few approaches are available for treatment of MM, it is still considered as an incurable disease globally. Therefore, the identification and validation of potential MM targets would be beneficial for the diagnosis and treatment of MM. In the present study, proteome alterations of MNCs from patients with MM were compared with MNCs from patients with non-hematological malignancies, as controls. Using LFQ based label-free proteomic analysis, 192 DE proteins were identified in MNCs from patients with MM compared with that in MNCs from patients with non-hematological malignancies. It was found that the protein and mRNA expression levels of MZB1 were significantly increased in the MNCs from patients with MM. Therefore, it was interesting to investigate the correlation between the accumulation of MZB1 and MM pathogenesis.

MZB1, also known as plasma cell induced endoplasmic reticulum protein, has been reported to have a role in the assembly and secretion of IgM antibodies from plasma cells $(34,45)$. MZB1 was also found to be involved in the integrin-mediated adhesion, endoplasmic reticulum calcium storage and calcium homeostasis (35). In addition, MZB1 was reported to be a highly expressed protein in patients with systemic lupus erythematosus (SLE) and has been reported as a potential therapeutic target for SLE (46). MZB1 acts as a tumor suppressor protein in some solid cancers, such as hepatocellular cancer and gastric cancer, and suppression of MZB1 lead to increase in proliferation and invasion of the cancerous cells $(47,48)$. In contrast, high levels of MZB1 are associated with adverse prognosis in hematological malignancies, such as chronic lymphocytic leukemia, follicular lymphoma and diffuse large cell lymphoma (49). MZB1 is associated with IgM heavy and light chains and promotes IgM assembly, as well as secretion. MZB1 is a GRP94 co-chaperone that enables biosynthesis of IgM heavy chain and is also involved in the association of the $\operatorname{IgM}$ heavy chain with the Ig surrogate light chains (45). Therefore it may play a key role in B cell neoplasms, such as MM. As with other hematological malignancies, the present study revealed that mRNA and protein expression levels of MZB1 were increased in patients with MM and functional studies revealed that high expression levels of MZB1 are associated with the malignant potential of MM. Furthermore, isolation of different types of cells ( $\mathrm{T}$ cells, B cells, dendritic cells and natural killer cells) from the bone marrow aspiration samples in patients with MM to examine MZB1 expression however the number of cells obtained was too few to perform proteomics or WB analysis. However, following a literature review to investigate the protein expression levels of MZB1 in various cell types (T cells, B cells, dendritic cells and natural killer cells), it was found that the MZB1 protein is primarily expressed in $\mathrm{B}$ cells, as well as dendritic cells (50). As plasma cells are the derivative cells of B cells, we hypothesize that MZB1 would be expressed in all types of plasma cells. STRING analysis of the 79 upregulated proteins identified in the present study revealed the direct interaction of MZB1 with IGJ. A previous study reported that MZB1 is involved in IgM heavy and light chain assembly and secretion (45). Furthermore, the protein expression level of MZB1 is reported to be increased during the differentiation of plasma cells and aids in the oxidative folding of Ig heavy chains (34). In the present study, Ig chain-related protein, such as IGJ, was found to be upregulated and had strong interactions with MZB1. High expression of IGJ protein has been reported to be associated with the poor survival in patients with acute lymphoblastic leukemia and of Hispanic descent (51). Furthermore, it was found that the knockdown of MZB1 reduced the proliferation of MM cells. Therefore, the high expression levels of MZB1, and IGJ, as well as their interactions together might be involved in the malignancy of MM.

The IPA network analysis revealed that MZB1 interacts with Ig, such as IGHM, IgA, IgG, IgM, IGHG3, JCHAIN, IgG1, IgG3 and IGHG2. These results are strongly correlated with characteristics of MM i.e., overproduction of antibodies. Notably, the majority of the antibodies found in the present study were found to be upregulated. Furthermore, MZB1 also showed strong interactions with CLU, which plays a key role in cancer metastasis (52). Moreover, IPA based toxicology functions of MNCs dysregulated proteins from patients with MM revealed their involvement in the elevation of creatinine levels, as well as decreased levels of albumin, which are basic pathological characteristic features of MM $(53,54)$. 
To verify the expression levels of MZB1 in MM, the protein levels in serum and BMIF from patients with MM was invetsigated. The results from WB analysis were consistent with the quantitative proteomic data of MNCs. Furthermore, functional studies using the MM RPMI-8226 cell line model was performed to understand the role of this protein in the pathogenesis of MM. Functional assays, such as cell proliferation assay, flow cytometry-based cell cycle analysis and soft agar colony formation assays revealed the involvement of MZB1 protein in the progression of MM. The cell proliferation assay demonstrated that the knockdown of MZB1 slowed the proliferation of RPMI-8226 cells.

Several studies have demonstrated that AKT is constitutively activated in MM, and activation of AKT signaling pathway plays an important role in the survival, proliferation and migration of MM cells $(55,56)$. Notably, the results from the present study revealed that MZB1 plays a crucial role in the activation of the AKT pathway and could be involved in the pathogenesis of MM. Likewise, the MAPK signaling pathway is important in the pathogenesis of MM, as it mediates MM cell growth as well as survival and upregulation of the MAPK signalling molecules leading to increased proliferation of MM cells $(38,57)$. The present study also demonstrated that MZB1 has an important role in the activation of the MAPK pathway. Therefore, the knockdown of MZB1 results in marked inactivation of AKT, as well as the MAPK pathways. Hence, MZB1 promotes the proliferation of MM cells, in part, through controlling the activation of AKT and MAPK pathways.

Cell cycle progression is associated with the expression levels of different cyclins, such as cyclin D1, cyclin A and cyclin B (39-41). It was found that MZB1 augments the protein expression levels of cyclin D1, cyclin A and cyclin B (Fig. 6). Cyclin D1 forms a complex with CDK4/CDK6 and monitors the progression of the $G_{1}$ phase of the cell cycle. Likewise, cyclin A forms complex with CDK2/CDK1 to facilitate the progression of $S$ phase, $G_{2}$ phase and early mitosis and cyclin $B$ forms a complex with CDK1 and thereby controls the progression of prometaphase to anaphase of the cell cycle (49-51). Previous studies have shown that high expression levels of the aforementioned cyclins promotes the progression of $\mathrm{MM}$ plasma cells in the cell cycle (58-60). Therefore, MZB1, at least in part, could accelerate the cell cycle progression of MM plasma cells and lead to malignancy. Overall, the results from the present study reveals that the MZB1 protein could be a potential diagnostic or therapeutic target for $\mathrm{MM}$, however, the use of a single MM cell line is one of the limitations and further investigations in additional MM cell lines is required to validate the findings.

In summary, quantitative proteomic profiling of the MNCs from patients with MM compared with that in patients with non-hematological malignant revealed that 192 proteins are DE. Knockdown of MZB1 results in inhibition of MM cell proliferation, anchorage-independent growth potential and induction of apoptosis suggesting that MZB1 is associated with progression of MM. Therefore, MZB1 could function as a putative oncogene in the pathogenesis of MM and might be a potential biomarker. Further studies are required to validate the findings from the present study in an animal model, as well as in a large cohort of MM samples, to establish the role of
MZB1 in MM, which could be translated into the efficient and successful clinical management of MM in the future.

\section{Acknowledgements}

The authors would like to thank Professor Michael R. Green (Department of Molecular, Cell and Cancer Biology, University of Massachusetts Medical School, Worcester, MA, USA) for the 293T cells.

\section{Funding}

This research was supported by the National Centre for Cell Science intramural funding, and the Department of Biotechnology, Government of India (grant no. BT/PR10855/ $\mathrm{BRB} / 10 / 1330 / 2014)$.

\section{Availability of data and materials}

MS proteomics datahave beendeposited to the ProteomeXchange Consortium via the PRIDE (61) partner repository with the dataset identifier PXD015598. The datasets generated and/or analyzed during the current study are available in the [PRIDE] repository (https://www.ebi.ac.uk/pride/archive/).

\section{Authors' contributions}

VC, MKS and SR conceived the study. VC, DP, SS, TC, MKS and SR designed the study. VC, DP and SI performed the experiments. VC, DP, KT, AS,SI and SR analyzed the data. VC, $\mathrm{DP}, \mathrm{KT}, \mathrm{AS}$ and SR analyzed the proteomics data, performed the statistical analysis and bioinformatics. VC, DP, KT, SS, TC, AS, MKS and SR drafted the manuscript. SR provided chemicals and reagents. All authors have read and approved the final manuscript.

\section{Ethics approval and consent to participate}

This study was approved by the Ethical Committee of National Centre for Cell Science (Pune, India) and Armed Forces Medical College (Pune, India; Insitutional Review Board no. NCCS/IEC/2016-I/8. Written informed consent was provided from all patients prior to collection of bone marrow aspirate and serum samples.

\section{Patient consent for publication}

Not applicable.

\section{Competing interests}

The authors confirm that they have no competing interests.

\section{References}

1. Hideshima T, Bergsagel PL, Kuehl WM and Anderson KC: Advances in biology of multiple myeloma: Clinical applications. Blood 104: 607-618, 2004.

2. Ge F, Tao S, Bi L, Zhang Z and Zhang X: Proteomics: Addressing the challenges of multiple myeloma. Acta Biochim Biophys Sin (Shanghai) 43: 89-95, 2011. 
3. Minnema MC, van der Spek E, van de Donk NW and Lokhorst HM: New developments in the treatment of patients with multiple myeloma. Neth J Med 68: 24-32, 2010.

4. Hussein MA: Multiple myeloma: Most common end-organ damage and management. J Natl Compr Canc Netw 5: 170-178, 2007.

5. Doshi M, Lahoti A, Danesh FR, Batuman V and Sanders PW; American Society of Nephrology Onco-Nephrology Forum: Paraprotein-Related Kidney Disease: Kidney Injury from Paraproteins-What Determines the Site of Injury? Clin J Am Soc Nephrol 11: 2288-2294, 2016.

6. Rajkumar SV, Dimopoulos MA, Palumbo A, Blade J, Merlini G, Mateos MV, Kumar S, Hillengass J, Kastritis E, Richardson P, et al: International Myeloma Working Group updated criteria for the diagnosis of multiple myeloma. Lancet Oncol 15: e538-e548, 2014.

7. Avet-Loiseau H, Malard F, Campion L, Magrangeas F, Sebban C, Lioure B, Decaux O, Lamy T, Legros L, Fuzibet JG, et al; Intergroupe Francophone du Myélome: Translocation t $(14 ; 16)$ and multiple myeloma: Is it really an independent prognostic factor? Blood 117: 2009-2011, 2011.

8. Corre J, Munshi N and Avet-Loiseau H: Genetics of multiple myeloma: Another heterogeneity level? Blood 125: 1870-1876, 2015.

9. Smadja NV, Fruchart C, Isnard F, Louvet C, Dutel JL, Cheron N, Grange MJ, Monconduit M and Bastard C: Chromosomal analysis in multiple myeloma: Cytogenetic evidence of two different diseases. Leukemia 12: 960-969, 1998.

10. Tremblay D: Novel targets in multiple myeloma. Am J Hematol Oncol 12: 18-25, 2017

11. Hanbali A, Hassanein M, Rasheed W, Aljurf M and Alsharif F: The evolution of prognostic factors in multiple myeloma. Adv Hematol 2017: 48126372017.

12. Alaoui-Jamali MA and $\mathrm{Xu}$ YJ: Proteomic technology for biomarker profiling in cancer: An update. J Zhejiang Univ Sci B 7: 411-420, 2006.

13. Gholami AM, Hahne H, Wu Z, Auer FJ, Meng C, Wilhelm M and Kuster B: Global proteome analysis of the NCI-60 cell line panel. Cell Rep 4: 609-620, 2013

14. Aslam B, Basit M, Nisar MA, Khurshid M and Rasool MH: Proteomics: Technologies and their applications. J Chromatogr Sci 55: 182-196, 2017.

15. Chanukuppa V, Taware R, Chatterjee T, Sharma S, More TH, Taunk K, Kumar S, Santra MK and Rapole S: Current Understanding of the Potential of Proteomics and Metabolomics Approaches in Cancer Chemoresistance: A Focus on Multiple Myeloma. Curr Top Med Chem 18: 2584-2598, 2018.

16. Amaya M, Baer A, Voss K, Campbell C, Mueller C, Bailey C, Kehn-Hall K, Petricoin E III and Narayanan A: Proteomic strategies for the discovery of novel diagnostic and therapeutic targets for infectious diseases. Pathog Dis 71: 177-189, 2014.

17. Nagaraj NS, Singh OV and Merchant NB: Proteomics: A strategy to understand the novel targets in protein misfolding and cancer therapy. Expert Rev Proteomics 7: 613-623, 2010.

18. Moseley FL, Bicknell KA, Marber MS and Brooks G: The use of proteomics to identify novel therapeutic targets for the treatment of disease. J Pharm Pharmacol 59: 609-628, 2007.

19. Ma TZ, Piao Z, Jin SY and Kwak YG: Differential expression of serum proteins in multiple myeloma. Exp Ther Med 17: 649-656, 2019.

20. Bai J, Yang Y, Wang J, Zhang L, Wang F and He A: Variability of serum novel serum peptide biomarkers correlates with the disease states of multiple myeloma. Clin Proteomics 16: 17, 2019.

21. Fernando RC, de Carvalho F, Mazzotti DR, Evangelista AF Braga WMT, de Lourdes Chauffaille M, Leme AFP and Colleoni GWB: Multiple myeloma cell lines and primary tumors proteoma: Protein biosynthesis and immune system as potential therapeutic targets. Genes Cancer 6: 462-471, 2015.

22. Sasikala P, Harsha C, Bajaj J, Sharma R, Pandey A and Krishna S: Quantitative Proteomic Profiling Unravels Dynamic Changes in the Myeloma Cell Proteome Treated with Valproic Acid (VPA). Blood 118: 1847, 2011.

23. Chanukuppa V, Paul D, Taunk K, Chatterjee T, Sharma S, Kumar S, Santra MK and Rapole S: XPO1 is a critical player for bortezomib resistance in multiple myeloma: A quantitative proteomic approach. J Proteomics 209: 103504, 2019.

24. Tripathy S: The role of serum protein electrophoresis in the detection of multiple myeloma: An experience of a corporate hospital. J Clin Diagn Res 6: 1458-1461, 2012.
25. Tosi P, Tomassetti S, Merli A and Polli V: Serum free light-chain assay for the detection and monitoring of multiple myeloma and related conditions. Ther Adv Hematol 4: 37-41, 2013.

26. Gerecke C, Fuhrmann S, Strifler S, Schmidt-Hieber M, Einsele H and Knop S: The diagnosis and treatment of multiple myeloma. Dtsch Arztebl Int 113: 470-476, 2016.

27. Rajkumar SV and Kyle RA: Multiple myeloma: diagnosis and treatment. In: Mayo Clinic Proceedings. Vol 80. Elsevier, pp1371-1382, 2005.

28. Gajendra S, Jha B, Goel S, Sahni T, Sharma R, Shariq M, Jaiswal S and Sachdev R: Leishman and Giemsa stain: A new reliable staining technique for blood/bone marrow smears. Int J Lab Hematol 37: 774-782, 2015.

29. Livak KJ and Schmittgen TD: Analysis of relative gene expression data using real-time quantitative PCR and the $2-\Delta \Delta C T$ method. Methods 25: 402-408, 2001.

30. Gajbhiye A, Dabhi R, Taunk K, Jagadeeshaprasad MG, RoyChoudhury S, Mane A, Bayatigeri S, Chaudhury K, Santra MK and Rapole S: Multipronged quantitative proteomics reveals serum proteome alterations in breast cancer intrinsic subtypes. J Proteomics 163: 1-13, 2017.

31. Takata T, Ishigaki Y, Shimasaki T, Tsuchida H, Motoo Y, Hayashi A and Tomosugi N: Characterization of proteins secreted by pancreatic cancer cells with anticancer drug treatment in vitro. Oncol Rep 28: 1968-1976, 2012.

32. Tennant JR: Evaluation of the trypan blue technique for determination of cell viability. Transplantation 2: 685-694, 1964.

33. Courtenay VD: A soft agar colony assay for Lewis lung tumour and B16 melanoma taken directly from the mouse. Br J Cancer 34: 39-45, 1976.

34. Shimizu Y, Meunier L and Hendershot LM: pERp1 is significantly up-regulated during plasma cell differentiation and contributes to the oxidative folding of immunoglobulin. Proc Natl Acad Sci USA 106: 17013-17018, 2009.

35. Flach H, Rosenbaum M, Duchniewicz M, Kim S, Zhang SL, Cahalan MD, Mittler G and Grosschedl R: Mzb1 protein regulates calcium homeostasis, antibody secretion, and integrin activation in innate-like B cells. Immunity 33: 723-735, 2010

36. Mori S, Chang JT, Andrechek ER, Matsumura N, Baba T, Yao G, Kim JW, Gatza M, Murphy S and Nevins JR: Anchorage-independent cell growth signature identifies tumors with metastatic potential. Oncogene 28: 2796-2805, 2009.

37. Younes H, Leleu X, Hatjiharissi E, Moreau AS, Hideshima T, Richardson P, Anderson KC and Ghobrial IM: Targeting the phosphatidylinositol 3-kinase pathway in multiple myeloma. Clin Cancer Res 13: 3771-3775, 2007.

38. Jin Y and Dai Z: USO1 promotes tumor progression via activating Erk pathway in multiple myeloma cells. Biomed Pharmacother 78: 264-271, 2016

39. Alao JP: The regulation of cyclin D1 degradation: Roles in cancer development and the potential for therapeutic invention. Mol Cancer 6: 24, 2007.

40. Desdouets C, Matesic G, Molina CA, Foulkes NS, Sassone-Corsi P, Brechot $\mathrm{C}$ and Sobczak-Thepot J: Cell cycle regulation of cyclin A gene expression by the cyclic AMP-responsive transcription factors CREB and CREM. Mol Cell Biol 15: 3301-3309, 1995.

41. Hershko A: Mechanisms and regulation of the degradation of cyclin B. Philos Trans R Soc Lond B Biol Sci 354: 1571-1575, discussion 1575-1576, 1999.

42. Landgren O and Weiss BM: Patterns of monoclonal gammopathy of undetermined significance and multiple myeloma in various ethnic/racial groups: Support for genetic factors in pathogenesis. Leukemia 23: 1691-1697, 2009.

43. Rajkumar SV and Kyle RA (eds): Treatment of multiple myeloma and related disorders. Cambridge University Press, 2008.

44. Teras LR, DeSantis CE, Cerhan JR, Morton LM, Jemal A and Flowers CR: 2016 US lymphoid malignancy statistics by World Health Organization subtypes. CA Cancer J Clin 66: 443-459, 2016.

45. van Anken E, Pena F, Hafkemeijer N, Christis C, Romijn EP, Grauschopf U, Oorschot VM, Pertel T, Engels S, Ora A, et al: Efficient IgM assembly and secretion require the plasma cell induced endoplasmic reticulum protein pERp1. Proc Natl Acad Sci USA 106: 17019-17024, 2009.

46. Miyagawa-Hayashino A, Yoshifuji H, Kitagori K, Ito S, Oku T, Hirayama Y, Salah A, Nakajima T, Kiso K, Yamada N, et al: Increase of MZB1 in B cells in systemic lupus erythematosus: Proteomic analysis of biopsied lymph nodes. Arthritis Res Ther 20: 13, 2018. 
47. Matsumura S, Imoto I, Kozaki K, Matsui T, Muramatsu T, Furuta M, Tanaka S, Sakamoto M, Arii S and Inazawa J: Integrative array-based approach identifies MZB1 as a frequently methylated putative tumor suppressor in hepatocellular carcinoma. Clin Cancer Res 18: 3541-3551, 2012.

48. Kanda M, Tanaka C, Kobayashi D, Tanaka H, Shimizu D, Shibata M, Takami H, Hayashi M, Iwata N, Niwa Y, et al: Epigenetic suppression of the immunoregulator MZB1 is associated with the malignant phenotype of gastric cancer. Int J Cancer 139: 2290-2298, 2016.

49. Herold T, Mulaw MA, Jurinovic V, Seiler T, Metzeler KH, Dufour A, Schneider S, Kakadia PM, Spiekermann K, Mansmann U, et al: High expression of MZB1 predicts adverse prognosis in chronic lymphocytic leukemia, follicular lymphoma and diffuse large B-cell lymphoma and is associated with a unique gene expression signature. Leuk Lymphoma 54: 1652-1657, 2013.

50. Uhlén M, Fagerberg L, Hallström BM, Lindskog C, Oksvold P, Mardinoglu A, Sivertsson Å, Kampf C, Sjöstedt E, Asplund A, et al: Proteomics. Tissue-based map of the human proteome. Science 347: 1260419, 2015.

51. Cruz-Rodriguez N, Combita AL, Enciso LJ, Quijano SM, Pinzon PL, Lozano OC, Castillo JS, Li L, Bareño J, Cardozo C, et al: High expression of ID family and IGJ genes signature as predictor of low induction treatment response and worst survival in adult Hispanic patients with B-acute lymphoblastic leukemia. J Exp Clin Cancer Res 35: 64, 2016.

52. Peng M, Deng J, Zhou S, Tao T, Su Q, Yang X and Yang $X$ The role of Clusterin in cancer metastasis. Cancer Manag Res 11: 2405-2414, 2019

53. Faiman B, Tariman JD, Mangan PA and Spong J: Renal complications in multiple myeloma and related disorders: Survivorship care plan of the IMF Nurse Leadership Board. Clin J Onco Nurs 15: 66-76, 2011.
54. Kim JE, Yoo C, Lee DH, Kim SW, Lee JS and Suh C: Serum albumin level is a significant prognostic factor reflecting disease severity in symptomatic multiple myeloma. Ann Hematol 89: 391-397, 2010.

55. Zhu J, Wang M, Cao B, Hou T and Mao X: Targeting the phosphatidylinositol 3-kinase/AKT pathway for the treatment of multiple myeloma. Curr Med Chem 21: 3173-3187, 2014.

56. Xu H, Li J and Zhou ZG: NEAT1 promotes cell proliferation in multiple myeloma by activating PI3K/AKT pathway. Eur Rev Med Pharmacol Sci 22: 6403-6411, 2018.

57. Ohguchi H, Harada T, Sagawa M, Kikuchi S, Tai YT, Richardson PG, Hideshima T and Anderson KC: KDM6B modulates MAPK pathway mediating multiple myeloma cell growth and survival. Leukemia 31: 2661-2669, 2017.

58. Kubiczková L, Dúcka M, Sedlaříková L, Kryukov F, Hájek R and Sevčíková S: Cyclins D in regulation and dysregulation of the cell cycle in multiple myeloma. Klin Onkol 26: 313-318, 2013 (In Czech).

59. Quinn J, Glassford J, Percy L, Munson P, Marafioti T, Rodriguez-Justo $\mathrm{M}$ and Yong K: APRIL promotes cell-cycle progression in primary multiple myeloma cells: Influence of D-type cyclin group and translocation status. Blood 117: 890-901, 2011.

60. Ettari R, Pallio G, Pizzino G, Irrera N, Zappalà M, Maiorana S, Di Chio C, Altavilla D, Squadrito F and Bitto A: Non-covalent immunoproteasome inhibitors induce cell cycle arrest in multiple myeloma MM.1R cells. J Enzyme Inhib Med Chem 34: 1307-1313, 2019

61. Vizcaíno JA, Csordas A, del-Toro N, Dianes JA, Griss J, Lavidas I, Mayer G, Perez-Riverol Y, Reisinger F, Ternent T, et al: 2016 update of the PRIDE database and its related tools. Nucleic Acids Res 44 (D1): D447-D456, 2016. 